Full length article

\title{
An injectable platelet lysate-hyaluronic acid hydrogel supports cellular activities and induces chondrogenesis of encapsulated mesenchymal stem cells
}

\author{
Elaheh Jooybar ${ }^{a}$, Mohammad J. Abdekhodaie ${ }^{\mathrm{a}, \mathrm{b}, *}$, Mansour Alvi $^{\mathrm{c}}$, Abbas Mousavi ${ }^{\mathrm{a}}$, Marcel Karperien ${ }^{\mathrm{d}}$, \\ Pieter J. Dijkstra ${ }^{\mathrm{d}, *}$ \\ a Department of Chemical Engineering, Sharif University of Technology, Tehran, Iran \\ ${ }^{\mathrm{b}}$ Environmental Applied Science and Management, Ryerson University, Toronto, Canada \\ ${ }^{\mathrm{c}}$ Canadian Center for Regenerative Therapy, Toronto, ON, Canada \\ ${ }^{\mathrm{d}}$ MIRA - Institute for Biomedical Technology and Technical Medicine and Department of Developmental BioEngineering, Faculty of Science and Technology, University of Twente, \\ PO Box 217, 7500 AE Enschede, The Netherlands
}

\section{A R T I C L E I N F O}

\section{Article history:}

Received 24 May 2018

Received in revised form 6 October 2018

Accepted 22 October 2018

Available online 24 October 2018

\section{Keywords:}

Platelet lysate

Injectable hydrogel

Hyaluronic acid

Mesenchymal stem cells

Enzymatic crosslinking

\begin{abstract}
A B S T R A C T
Developing scaffolds that can provide cells and biological cues simultaneously in the defect site is of interest in tissue engineering field. In this study, platelet lysate (PL) as an autologous and inexpensive source of growth factors was incorporated into a cell-laden injectable hyaluronic acid-tyramine (HATA) hydrogel. Subsequently, the effect of platelet lysate on cell attachment, viability and differentiation of human mesenchymal stem cell (hMSCs) toward chondrocytes was investigated. HA-TA conjugates having a degree of substitution of 20 TA moieties per 100 disaccharide units were prepared and crosslinked in the presence of horseradish peroxidase and low concentrations of hydrogen peroxide. The storage moduli of the gels ranged from 500 to $2000 \mathrm{~Pa}$ and increased with increasing polymer concentration. In contrast to a retained round shape of the cells when using pure HA-TA hydrogel, the hMSCs attached and spread out in PL enriched matrix. The enrichment of hMSCs laden HA-TA hydrogels with PL induced a cartilage like extra cellular matrix deposition in vitro. The hMSCs increasingly deposited collagen type II and proteoglycans over time. The deposition of the new extracellular matrix (ECM) is simultaneous with gel degradation and resulted ultimately in the formation of a tough dense matrix. These findings demonstrate the potential of injectable HA-TA-PL hydrogel as a cell delivery system for cartilage regeneration.
\end{abstract}

\section{Statement of Significance}

Cartilage tissue has limited ability to self-repair because of its avascular nature. To have an efficient cartilage tissue regeneration, we combined platelet lysate (PL), as an autologous and inexpensive source of growth factors, with an injectable hyaluronic acid tyramine (HA-TA) hydrogel scaffold. Platelet lysate had a vital role in supporting human mesenchymal stem cells (hMSCs) activities, like cell attachment, viability and proliferation in the 3D hydrogel structure. Also, the hMSCs encapsulated HA-TA induced hyaline cartilage generation when placed in chondrogenic differentiation medium. This study introduces a new system for cartilage tissue engineering, which can be injected in a minimally invasive manner and is rich with patient's own growth factors and biological cues.

(c) 2018 Acta Materialia Inc. Published by Elsevier Ltd. All rights reserved.
* Corresponding authors at: Department of Chemical Engineering, Sharif University of Technology, Tehran, Iran (M.J. Abdekhodaie).

E-mail addresses: abdmj@sharif.edu (M.J. Abdekhodaie),p.j.dijkstra@utwente.nl (P.J. Dijkstra).

\section{Introduction}

Articular cartilage is a highly organized tissue with low-friction, wear-resistant, and load-bearing properties allowing efficient joint movement [1]. About $70 \%$ of people aged over 65 suffer from a degenerative joint disease or osteoarthritis. However, because of avascular nature of the cartilage and its limited regenerative 
ability, the cartilage tissue is degraded progressively in case of diseases or trauma $[2,3]$. To stimulate cartilage regeneration, nowadays tissue engineering concepts play an important role in the repair of damaged cartilage tissue. To temporarily fill defects and stimulate regeneration, hydrogels in combination with biological components and cells have been widely investigated as proper scaffolds [4-6]. Among all types of hydrogels, injectable hydrogels, which can be placed locally as a viscous solution and form a stable physically or covalently crosslinked network, have received much attention. These in situ forming hydrogels have the advantages of eliminating invasive surgical procedures and capability of filling irregular defects [7-10].

Both natural and synthetic polymers have been employed for the development of injectable hydrogels [4]. Among those, hyaluronic acid (HA), a linear polysaccharide and a key component in the cartilage extracellular matrix has received wide-spread attention in cartilage tissue engineering [11-13]. Hyaluronic acid is a biodegradable and biocompatible material with stimulatory effects on cell migration, proliferation, ECM secretion and differentiation [14-18]. The presence of functional groups like hydroxyl and carboxyl groups in HA provides anchors for various chemical modifications, important in the design and properties of injectable hydrogels [19-21]. A very efficient methodology is the enzymatic crosslinking of hyaluronic acid conjugates. In a paper on the Horseradish peroxidase crosslinking of, amongst others, tyramine conjugates of polypeptides by Kaplan and coworkers, the efficiency of this method was shown [22]. Kurisawa and coworkers were the first to prepare hyaluronic acid tyramine conjugate hydrogels and show their enzymatic crosslinking [23]. Not only Horseradish peroxidase but also other enzymes, as shown e.g. by the group of Sakai, may be used as efficient catalysts in crosslinking reactions of polysaccharide conjugates [24]. Enzymatic crosslinking as a method to in situ forming hydrogels can be applied under mild conditions in the presence of low concentrations of hydrogen peroxide $\left(\mathrm{H}_{2} \mathrm{O}_{2}\right)$. By changing the amount of the enzyme and $\mathrm{H}_{2} \mathrm{O}_{2}$, and also degree of substitution (DS) of tyramine groups to the $\mathrm{HA}$, the gelation time, mechanical strength and degradation properties of the hydrogels can be tuned $[23,25,26]$.

Hydrogels can be used as scaffolds for cell therapy, as they are able to mimic the native ECM with their high water content and soft structure [27]. They can protect cells from local biochemical influences and enhance cell viability, proliferation and retention [25,28-30]. Cells can be located in the structure of in situ forming hydrogels by suspending them homogeneously in the precursor solutions prior to gelation. Among different types of cells, stem cells are a good candidate for tissue regeneration purposes because of their self-renewal ability, and potential to differentiate into many cell types $[31,32]$. However, similarly as in natural tissue regeneration, physical and chemical factors are needed to stimulate cellular activities like cell adhesion sites and the presentation of soluble factors including cytokines and growth factors [33].

Platelet lysate (PL) contains, amongst major proteins like albumin and fibrinogen, a cocktail of autologous growth factors and biochemical signals and is obtained from the peripheral blood of patients. In some studies it was shown that platelet lysate potentiates cell proliferation, migration and also chondrogenic differentiation [34-37]. Platelet concentrates are utilized in the medical field for their availability, cost effectiveness and autologous nature $[36,38]$. PL loaded scaffolds have more recently been investigated for cartilage [37] and bone [39] regeneration, and also wound healing [40]. As a new therapy for osteoarthritis (OA), autologous platelet rich plasma (PRP) was injected in the knee joint 2 or 3 times weekly $[41,42]$. Preliminary results indicated that PRP is safe and can reduce pain and improve joint function [43-46]. However, despite the promising findings, the efficacy of using PRP for treat- ing cartilage defect has remained controversial [47-49]. Variation in the platelet concentration provided by different preparation protocols may have a large impact on the clinical outcomes. Also, the growth factors content in the platelets is different between individuals which may affect the healing process [50].

In this study, tyramine conjugated hyaluronic acid was synthesized and physical properties of the enzymatically crosslinked hydrogel like gelation times, swelling ratio and storage moduli were evaluated. PL, as an autologous source of different bioactive proteins, and human mesenchymal stem cells were incorporated in the injectable hyaluronic acid-tyramine (HA-TA) hydrogel and the effect of PL on viability, proliferation and chondrogenic differentiation of the encapsulated stem cells were studied. The expression of cartilage markers was analyzed using real-time PCR, and the production of a cartilage-specific matrix like proteoglycans and collagen type II were examined. Developing such a system, which is injected in a minimally invasive manner and is rich with patient's own growth factors and biological cues, can be used for cartilage repair with expectedly superior outcome compared to PL injection in office settings.

\section{Materials and methods}

\subsection{Materials}

Sodium hyaluronate (MW $=70 \mathrm{kDa}$ ) was purchased from HTL SAS (Javené, France) and used without further purification. Tyramine (TA) (99\%), anhydrous N,N-dimethylformamide (DMF) (99.8\%), N-(3-dimethylaminopropyl)-N'-ethylcarbodiimide hydrochloride (EDAC), N-hydroxysuccinimide (NHS), hydrogen peroxide $\left(\mathrm{H}_{2} \mathrm{O}_{2}\right)$, and horseradish peroxidase (HRP, 325 units/mg solid), Hyaluronidase from bovine testes (lyophilized powder, 400-1000 units/mg), MES hemisodium salt dry powder, were obtained from Sigma-Aldrich and used without further purification. Phosphate buffered saline (PBS, $10 \mathrm{mM}, \mathrm{pH}$ 7.4) was purchased from Lonza. All other solvents were purchased from Biosolve (Valkenswaard, The Netherlands) and used as received. Platelet lysate and Heparin sodium salt solution (5000 U/ml) were purchased from PL BioScience (Aachen, Germany)

\subsection{Synthesis of $H A-T A$}

Typically, sodium hyaluronate $(1.0 \mathrm{~g}, 2.5 \mathrm{mmol}$ of $\mathrm{COOH}$ groups) was dissolved in $30 \mathrm{~mL}$ of PBS. EDAC $(1.0 \mathrm{~g}, 5.2 \mathrm{mmol})$ and NHS ( $1.3 \mathrm{~g}, 11.3 \mathrm{mmol}$ ) were added and the solution was stirred for $2 \mathrm{~h}$. The product was precipitated in cold ethanol, filtered and washed with ethanol and finally diethyl ether. The polymer with NHS activated $\mathrm{COOH}$ groups $(1.0 \mathrm{~g})$ was dissolved in $30 \mathrm{~mL}$ of $0.1 \mathrm{M}$ MES buffer. Tyramine (385 mg, $2.8 \mathrm{mmol}$ ) was dissolved in $4 \mathrm{~mL}$ of DMF and added to the solution. The $\mathrm{pH}$ of the solution before tyramine addition was 6.1 and after that was directly adjusted to $\mathrm{pH} 7$ by the addition of $2 \mathrm{M}$ HCL. After overnight stirring, the resulting solution was precipitated in cold ethanol, filtered and washed with ethanol and finally diethyl ether. The resulting white powder was dissolved in MilliQ-water and dialyzed (Pre-wetted RC tubing, Spectrum Labs, MWCO 1000), first against $100 \mathrm{mM}$ sodium chloride solution for 2 days, followed by a mixture of distilled water and ethanol (5:1) for 1 day and MilliQ-water for 1 day. The HA-TA conjugate was obtained after lyophilization as a white foam. The degree of substitution (DS), defined as the number of substituted groups per 100 disaccharide units, was calculated from ${ }^{1} \mathrm{H}$ NMR $\left(\mathrm{D}_{2} \mathrm{O}\right)$ spectral data by comparing the integral values of the aromatic protons of tyramine (peaks at 6.86 and $7.17 \mathrm{ppm}$ ) and the methyl protons of HA (1.9 ppm). 


\subsection{Hydrogel preparation and gelation time}

The HA-TA was dissolved in PBS at concentrations of 1,2 or $4 \%$ $\mathrm{w} / \mathrm{v}$. A freshly made HRP and $\mathrm{H}_{2} \mathrm{O}_{2}$ solution in PBS were added and the mixture was gently mixed to form a gel. An amount of 0.2-0.6 mg HRP per mmol of phenol moieties and $\mathrm{H}_{2} \mathrm{O}_{2} /$ TA molar ratio of between 0.1 and 0.5 were applied. In a typical example, to a PBS solution of HA-TA ( $1 \mathrm{~mL}, 2 \% \mathrm{w} / \mathrm{v}), 10 \mu \mathrm{L}$ of $\mathrm{H}_{2} \mathrm{O}_{2}(1.5 \% \mathrm{v} /$ v) and $2.5 \mu \mathrm{L} \mathrm{HRP}(0.5 \mathrm{mg} / \mathrm{ml}, 162.5 \mathrm{U} / \mathrm{ml})$ were added. The concentration of $\mathrm{HRP}$ and $\mathrm{H}_{2} \mathrm{O}_{2}$ in the final solution was $4.9 \mathrm{mM}$ and $0.4 \mathrm{U} / \mathrm{ml}$, respectively. For developing platelet lysate incorporated hydrogels (HA-TA-PL constructs), HA-TA was dissolved in 50\% (50\% PBS) or $100 \%$ PL (pure PL) solution. The hydrogels with $50 \%$ and $100 \%$ PL were named HA-TA-PL50 and HA-TA-PL100, respectively. The platelet lysate was filtered using a $0.22 \mu \mathrm{m}$ syringe filter before use. Heparin, at a final concentration of $2 \mathrm{U} / \mathrm{ml}$, was added to the PL solution to prevent unwanted coagulation. Gelation times were determined with the vial tilting method. No flow upon inverting the vial was regarded as the gel state.

\subsection{Physical characterization of hydrogel}

The swelling ratio of HA-TA and HA-TA-PL hydrogels were calculated based on the weight of wet to dry hydrogel at different time points. Hydrogels were incubated in PBS at $37^{\circ} \mathrm{C}$ and at different time intervals, the hydrogels were removed, excess of water was wiped with a tissue, and weighed $\left(\mathrm{W}_{\mathrm{w}}\right)$. The hydrogels were dried in oven at $37^{\circ} \mathrm{C}$ overnight to obtain the dry weight $\left(\mathrm{W}_{\mathrm{d}}\right)$. The swelling ratio is expressed as the ratio of wet to dry weight $\left(\mathrm{W}_{\mathrm{w}} / \mathrm{W}_{\mathrm{d}}\right)$.

Rheological experiments were carried out with a MCR 301 rheometer (Anton Paar) using a parallel plate configuration (25 mm diameter, $0^{\circ}$ ) at $37^{\circ} \mathrm{C}$ in the oscillatory mode. In a typical experiment, fresh solutions of HRP and $\mathrm{H}_{2} \mathrm{O}_{2}$ were added to different concentrations of the HA-TA dissolved in PBS or PL. The reaction conditions were $0.2 \mathrm{mg}$ of HRP per mmol of phenol groups and different molar ratios of $\mathrm{H}_{2} \mathrm{O}_{2} /$ TA to provide for various crosslinking densities. The hydrogels were made in a mold with $20 \mathrm{~mm}$ diameter and height of $3 \mathrm{~mm}$. Hydrogels were subsequently put in PBS and incubated at $37{ }^{\circ} \mathrm{C}$ overnight. The resulting gels were placed at the ground plate and the upper plate was lowered to a measuring gap size of approximately $3 \mathrm{~mm}$ to an initial force of $0.5 \mathrm{~N} / \mathrm{m}^{2}$. The storage $\left(\mathrm{G}^{\prime}\right)$ modulus was recorded using a strain of $1 \%$ and a frequency of $1 \mathrm{~Hz}$.

\subsection{In vitro enzymatic degradation}

On top of a $200 \mu \mathrm{L}$ hydrogel $2 \mathrm{~mL}$ of PBS containing 50 or $0.5 \mathrm{U} /$ $\mathrm{ml}$ of Hyaluronidase was placed. The samples were incubated at $37^{\circ} \mathrm{C}$. At different time points the hydrogels were removed, wiped with tissue and weighed (Wt). The hyaluronidase solution was refreshed every 2-3 days. The results are shown as the mass fraction of the original gel weight (Wi). The degradation time was defined as the time required to completely dissolve the hydrogel $(n=3)$.

\subsection{Encapsulation of hMSCs in hydrogel}

Human bone marrow derived mesenchymal stem cells were isolated as previously reported [51], and cultured in MSC proliferation medium ( $\alpha$-MEM (Gibco) supplemented with $10 \%$ fetal bovine serum, 1\% L-glutamine (Gibco), $0.2 \mathrm{mM}$ ascorbic acid (Gibco), $100 \mathrm{U} / \mathrm{mL}$ penicillin, $10 \mu \mathrm{g} / \mathrm{mL}$ streptomycin and $1 \mathrm{ng} / \mathrm{mL}$ bFGF). The use of human material was approved by a local medical ethical committee. All reagents used were purchased from Invitrogen (Paisley, UK) unless otherwise stated.

Hydrogels containing hMSCs were prepared under sterile conditions by mixing precursor gel solutions and a cell suspension as described below. Gel precursor solutions of HA-TA and HA-TA-PL were made using PBS and platelet lysate, respectively, and HRP and $\mathrm{H}_{2} \mathrm{O}_{2}$ stock solutions were made using PBS. The cell/gel constructs were made in a 96 round-bottom well plate. The final concentration of HA-TA was $2 \%(\mathrm{w} / \mathrm{v})$ and the cell seeding density in the gels was 10 million cells $/ \mathrm{mL}$. Typically, $0.5 \mathrm{~mL}$ of a HA-TA polymer solution $(2 \%(\mathrm{w} / \mathrm{v})$ ) containing HRP (concentration of $8 \mathrm{U} / \mathrm{mL}$ ) was added to a hMSC pellet $\left(10 \times 10^{6}\right.$ cells $)$, and cells were resuspended by gently mixing. Separately, $0.5 \mathrm{~mL}$ of a HA-TA solution (2\% $(\mathrm{w} / \mathrm{v})$ ) containing $\mathrm{H}_{2} \mathrm{O}_{2}$ (concentration of $9.8 \mathrm{mM}$ ) was prepared. Mixing of $20 \mu \mathrm{L}$ of the solutions afforded $40 \mu \mathrm{L}$ hydrogels. The final concentrations of $\mathrm{H}_{2} \mathrm{O}_{2}$ and HRP were $4.9 \mathrm{mM}$ and $4 \mathrm{U} /$ $\mathrm{ml}$, respectively. After gelation, gels were removed from the 96-well plate and put into a 48 -well plate with $500 \mu \mathrm{L}$ of hMSC proliferation medium without bFGF. The culture medium was exchanged every 2 or 3 days.

\section{7. hMSCs attachment, spreading and morphology}

Using phase contrast microscopy, cell spreading in time in the different gel constructs was analyzed. To visualize F-Actin expression in encapsulated cells and the nuclei, FITC-labeled phalloidin and Dapi (Invitrogen) were used, respectively. Samples were harvested and put in $10 \%$ formalin overnight. Then, the samples were permeabilized using $0.1 \% \mathrm{v} / \mathrm{v}$ Triton X 100 in PBS. FITC-labeled Phalloidin was applied to the samples in a dilution of 1:40 followed by incubation for $30 \mathrm{~min}$ at room temperature in the dark. Then Dapi was added to counterstain the cell nuclei. After staining, cells were imaged using an EVOS digital microscope (Invitrogen, Netherlands).

\subsection{Cell viability}

Cell viability of the encapsulated cells was assayed by Live/dead kit at days 7 and 14. The hydrogel constructs were rinsed with PBS twice for 10 min each and then stained with calcein AM/ethidium homodimer using the Live-dead assay Kit (Invitrogen) according to the manufacturer's instructions. Hydrogel/cell constructs were visualized using a fluorescence microscope (EVOS). Living cells fluoresce green and the nuclei of dead cells red. Live/Dead staining also indicated the spreading of the cells in the hydrogels. Additionally, metabolic activity of the encapsulated cells was measured using a Prestoblue assay (Invitrogen). Briefly, samples were incubated with a $10 \%$ solution of Prestoblue in culture medium for $2 \mathrm{~h}$. The absorbance was measured using a microplate reader at $560 \mathrm{~nm}$ excitation and $590 \mathrm{~nm}$ emission. Data are presented as average \pm SD.

\subsection{DNA quantification}

The DNA content of the hydrogel/cell constructs was measured up to 14 days using a CyQuant DNA Assay kit according the manufacturer's description (Molecular Probes, Eugene, Oregon, USA), and using a fluorescent plate reader (excitation: $480 \mathrm{~nm}$; emission: $520 \mathrm{~nm}$ ) (Perkin-Elmer, Victor 3, USA). The hydrogels were washed with PBS and stored at $-80^{\circ} \mathrm{C}$. Prior to the assay, $1 \mathrm{~mL}$ of CDP-Star lysis buffer (Roche) was added to each hydrogel and the samples were smashed, homogenized, and incubated for one hour at room temperature. The standard curve for DNA analysis was generated with $\lambda$ DNA included in the kit. 


\subsection{Chondrogenic differentiation}

HA-TA hydrogel samples ( $40 \mu \mathrm{L}, 2 \%(\mathrm{w} / \mathrm{v}))$ with or without platelet lysate were prepared with $1 * 10^{7}$ cells $/ \mathrm{mL}$ of passage $4 \mathrm{hMSCs}$, and gelation was induced by HRP and $\mathrm{H}_{2} \mathrm{O}_{2}$ as described above. To each gel, $0.5 \mathrm{~mL}$ of chondrogenic medium composed of DMEM supplemented with $0.1 \mathrm{mM}$ dexamethasone (Sigma), $50 \mathrm{mg} / \mathrm{mL}$ ascorbic acid, $100 \mathrm{mg} / \mathrm{mL}$ sodium pyruvate (Sigma), $40 \mathrm{mg} / \mathrm{mL}$ L-proline, $1 \%$ insulin-transferrin selenous acid-plus premix (BD Bioscience Pharmingen), $100 \mathrm{U} / \mathrm{mL}$ penicillin, $100 \mathrm{mg} / \mathrm{mL}$ streptomycin, and $10 \mathrm{ng} / \mathrm{mL}$ Transforming Growth Factor (TGF- $\beta 3$ ) (R\&D Systems), was added. hMSCs were retrieved from a single donor. For each condition three samples were cultured up to 35 days, and the culture medium was changed every two days.

\subsection{Gene expression analysis}

The ability of hMSCs to differentiate to chondrocytes and to form cartilaginous tissue in vitro was evaluated after culturing gel-cell constructs in differentiation medium up to 35 Days. At different time intervals, the samples were harvested from the chondrogenic medium, $1 \mathrm{~mL}$ Trizol (Invitrogen, Carlsbad, CA) was added to each sample and then snap freezed in liquid nitrogen. The hydrogels were dissociated with GentleMACS ${ }^{\mathrm{TM}}$ Octo Dissociator. Total RNA was isolated from the lysate according to the Trizol Isolation protocol. The concentration of RNA was measured using the Nanodrop 2000 (ND-1000 Spectrophotometer, Isogen LifeScience). Subsequently, the RNA ( $1 \mu \mathrm{g}$ ) was reverse transcribed into single strand cDNA using the iScript Kit (BioRad) according to the manufacturer's recommendations. The cDNA sample was analyzed using the "SensiMix ${ }^{\mathrm{TM}}$ SYBR \& Fluorescein kit" (Bioline) and a realtime PCR Cycler (Bio-Rad CFX96, Hercules, CA). Gene expression of collagen type I, II and X, aggrecan, and SOX 9 (Table 1) were analyzed and normalized to the expression of the housekeeping gene glyceraldehyde-3-phosphate dehydrogenase (GAPDH) and fold changes were compared to those in the same group at day zero by using the $2^{-(\Delta \Delta \mathrm{Ct})}$ method. For each reaction, a melting curve was generated to test primer dimer formation and non-specific priming. Error bars were means \pm SD of three independent conditions, each measured in triplicates.

\subsection{Histological, immunohistochemical and SEM analysis}

Samples cultured for 28 days were fixed in $10 \%$ formalin overnight at $4{ }^{\circ} \mathrm{C}$ and then washed with PBS. Then, the samples were transferred to a cryomold, filled with Cryomatrix ${ }^{\mathrm{TM}}$ (Thermo Scientific), and frozen using liquid nitrogen. The samples were kept at $-80^{\circ} \mathrm{C}$ until cryosectioning. The sectioning was done using a cryostat (Cryotome ${ }^{\mathrm{TM}} \mathrm{FE}$ ) operating at $-20^{\circ} \mathrm{C}$. For each section, $10 \mu \mathrm{m}$ cross sections along the flat plane of the construct were collected on SuperFrost ${ }^{\circledR}$ Plus Gold slides (Fisher Scientific). The slides were kept at $-20^{\circ} \mathrm{C}$ until further analysis. Proteoglycan deposition and distribution was visualized by staining sections with Alcian blue and Safranin O. Typically, for Alcian blue staining, slides were stained for sulfated glycosaminoglycans (GAG) with a $0.5 \%(\mathrm{w} / \mathrm{v})$ solution of Alcian blue ( $\mathrm{pH}=1$, adjusted with $\mathrm{HCl}$ ) for 30 min. The samples were then counterstained with nuclear fast red $(0.1 \%(\mathrm{w} / \mathrm{v})$ of nuclear fast red in $5 \%$ aluminum sulfate) for $5 \mathrm{~min}$ to visualize nuclei. The slides were washed with water and dehydrated. For Safranin O staining, after rehydration, the samples were counterstained with haematoxylin and fast green. After rinsing with acetic acid solution $(1 \%, v / v)$, the sections were stained with Safranin O solution ( $0.1 \% \mathrm{v} / \mathrm{v})$ and dehydrated. The presence of collagen I and II in the construct was detected using a DAKO kit. Collagen I antibody (ab90395) and collagen II antibody (ab3092) were used in 1:200 dilutions. For the negative control, the staining procedure was performed without using a primary antibody. A Hamamatsu Nanozoomer was used to obtain histologically and immunohistochemically images. Scanning Electron Microscopy (SEM) was used to see secreted collagen fibers. The hydrogel samples were dehydrated using a graded ethanol series (50\% to $100 \%$ ), dried using hexamethyldisilazane (HMDS, Merck), gold sputtered (Cressington 108auto) and imaged (JEOL benchtop SEM).

\subsection{Statistical analysis}

Each experiment was performed in triplicate unless otherwise specified. The results are presented as mean \pm standard deviation (SD). Experimental data were analyzed for statistical significance using a one-way analysis of variance (ANOVA) with Turkey's post hoc analysis. Statistical significance was set to ${ }^{*} \mathrm{p}$-value $<0.05$, p-value $<0.01$, and ${ }^{* * *}$ p-value $<0.001$.

\section{Results}

\subsection{Hydrogel preparation and characterization}

The HA-TA conjugate was synthesized in a two-step procedure. First, part of the carboxylic acid groups of the hyaluronic acid were activated by conversion to NHS esters. The degree of substitution of carboxylic acid groups as determined form the ${ }^{1} \mathrm{H}$ NMR spectrum was $24 \%$. In the second step, the NHS esters were reacted with tyramine to provide the HA-TA. According to the ${ }^{1} \mathrm{H}$ NMR spectral data, the degree of substitution calculated from the integral ratio of the tyramine phenolic protons and the hyaluronic acid methyl protons was 20\% (Fig. S1). HA-TA hydrogels were prepared in a mold by addition of HRP and $\mathrm{H}_{2} \mathrm{O}_{2}$ to the polymer solutions. Gelation times of HA-TA solutions at different concentrations of $\mathrm{HRP}$ and at a fixed $\mathrm{H}_{2} \mathrm{O}_{2}$ /TA molar ratio of 0.25 (final concentration of $\mathrm{H}_{2} \mathrm{O}_{2}$ is 1.25 and $2.5 \mathrm{mM}$ for 1 and $2 \%(\mathrm{w} / \mathrm{v})$ polymer concentration, respectively) were determined by the vial tilting method (Fig. 1a). By increasing the $\mathrm{mgHRP} / \mathrm{mmolTA}$ ratio, the gel forms faster and gelation times as low as $10 \mathrm{~s}$ were observed. The swelling ratios of 1 and 2\% (w/v) HA-TA hydrogels prepared at a mgHRP/ mmolTA ratio of 0.3 and $\mathrm{H}_{2} \mathrm{O}_{2}$ /TA molar ratio of 0.5 are presented in Fig. $1 \mathrm{~b}$. After approximately three hours the degree of swelling reaches a plateau and is lower at a higher polymer concentration because of the more densely crosslinked network formed.

Table 1

Polymerase chain reaction primers.

\begin{tabular}{|c|c|c|}
\hline PCR Primer & Forward & Reverse \\
\hline Human ACAN & 5' AGGCAGCGTGATCCTTACC 3' & 5' GGCCTCTCCAGTCTCATTCTC 3' \\
\hline Human Col2A1 & 5' CGTCCAGATGACCTTCCTACG 3' & $5^{\prime}$ TGAGCAGGGCCTTCTTGAG $3^{\prime}$ \\
\hline Human Col1A1 & 5' GTCACCCACCGACCAAGAAACC 3' & 5' AAGTCCAGGCTGTCCAGGGATG 3' \\
\hline Human Col X & $5^{\prime}$ CTGTATAAGAATGGCACCCCTGTA 3' & 5' GCACTCCCTGAAGCCTGATC 3' \\
\hline Human SOX 9 & $5^{\prime}$ TGGAGACTTCTGAACGAGAGC $3^{\prime}$ & 5' CGTTCTTCACCCACTTCCTC 3' \\
\hline Human GAPDH & 5' CGCTCTCTGCTCCTCCTGTT 3' & 5' CCATGGTGTCTGAGCGATGT 3' \\
\hline
\end{tabular}



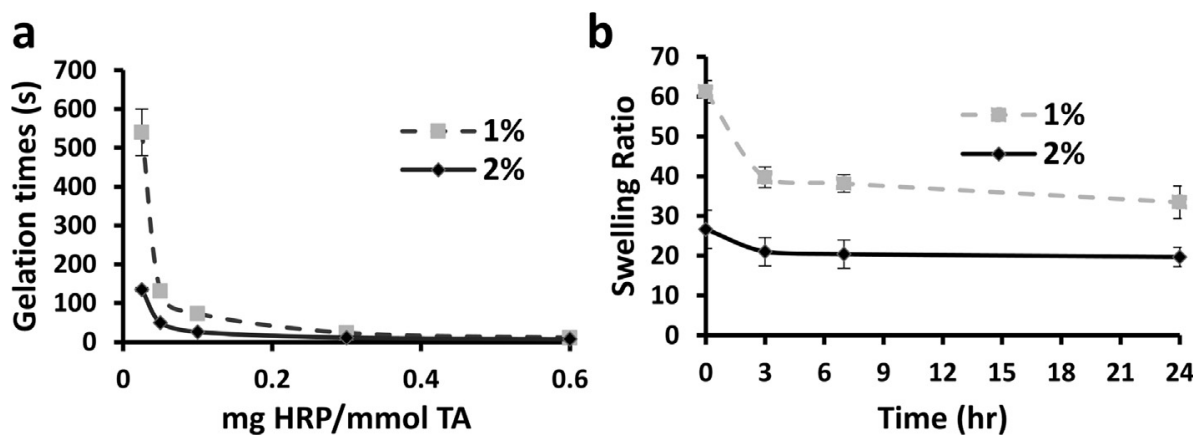

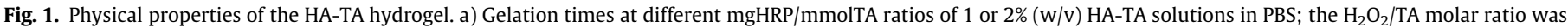
0.25 . b) Swelling behavior of hydrogels in time prepared at a mgHRP/mmolTA ratio of 0.2 and a $\mathrm{H}_{2} \mathrm{O}_{2} / \mathrm{TA}$ molar ratio of 0.5 .
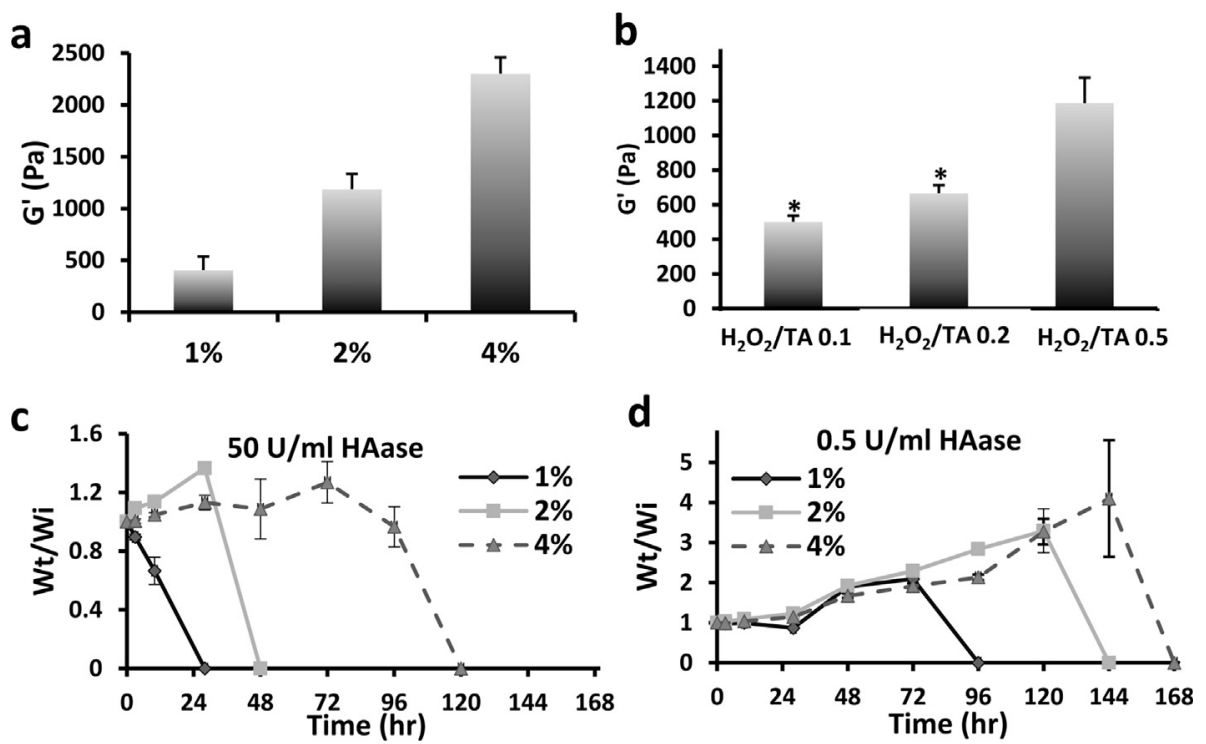

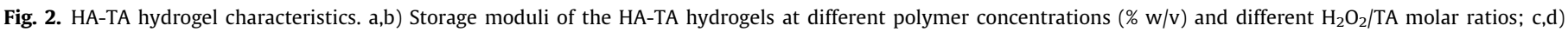
Enzymatic degradation of HA-TA hydrogels exposed to different concentrations of Hyaluronidase at $37^{\circ} \mathrm{C}$.

The storage moduli $\left(\mathrm{G}^{\prime}\right)$ of the HA-TA hydrogels after gelation were determined at $37^{\circ} \mathrm{C}$ by oscillatory rheology. As shown in Fig. 2a,b, an increase from $400 \pm 130$ to $2300 \pm 160$ Pa of the storage modulus is found when the polymer concentration was increased from 1 to $4 \%(\mathrm{w} / \mathrm{v})$. Changing the amount of $\mathrm{H}_{2} \mathrm{O}_{2}$ applied in hydrogel formation revealed that the storage modulus increased with an increased concentration of $\mathrm{H}_{2} \mathrm{O}_{2}$ as a result of more crosslinks formed. The storage modulus is highest at a $\mathrm{H}_{2} \mathrm{O}_{2} / \mathrm{TA}$ molar ratio of 0.5 which is the theoretical ratio needed for complete crosslinking assuming only coupling of radicals and absence of polymerization reactions.

Hyaluronic acid is known to be degraded in the presence of Hyaluronidase, present in most tissues. To determine the degradation profile, two enzyme concentrations were applied for hydrogels prepared at polymer concentrations of 1,2 and $4 \%$ (w/v) (Fig. 2c,d). The general trend observed for the degradation of HA-TA hydrogels is an increase in water uptake as a result of network cleavage followed by complete dissolution. By increasing the polymer concentration, because of the more densely crosslinked network formed, the degradation rate is lower.

\subsection{Effect of platelet lysate on hydrogel properties}

The storage moduli, swelling ratios and degradation of hydrogels prepared by dissolution in PBS (HA-TA), 50\% PL (HA-TA-
PL50) and $100 \%$ PL (HA-TA-PL100) were determined at a mgHRP/ mmolTA ratio of 0.2 and $\mathrm{H}_{2} \mathrm{O}_{2}$ /TA molar ratio of 0.5 , and results are presented in Fig. 3. The storage moduli of the HA-TA and HATA-PL50 hydrogels prepared appeared similar. Remarkably, when the PBS is fully replaced by platelet lysate (HA-TA-PL100) the storage modulus decreased (Fig. 3a). The likely presence of catalase in the platelet lysate, which is also present in the whole blood, decomposes the $\mathrm{H}_{2} \mathrm{O}_{2}$ and prevents complete crosslinking. Increasing the $\mathrm{H}_{2} \mathrm{O}_{2}$ /TA molar ratio to 1 , the storage modulus significantly increased 2.5-fold. Therefore, addition of excess $\mathrm{H}_{2} \mathrm{O}_{2}$ compensates the loss of oxidative reagent and a storage modulus value similar as determined for the HA-TA hydrogel was achieved. The time and trends for complete degradation observed were similar for all hydrogels independent of the use of platelet lysate (Fig. 3c). The swelling ratios for the HA-TA and HA-TA-PL50 were similar, but for HA-TA-PL100 appears lower (Fig. 3b). In line with the swelling ratio results, during degradation, the $\mathrm{Wt} / \mathrm{Wi}$ ratio for the HA-TA-PL100 was somewhat lower compared to the HA-TA and HA-TA-PL50 hydrogels.

\section{3. $3 D$ cultivation of hMSCs}

The effect of platelet lysate on cell adhesion and morphology was investigated by encapsulating hMSCs in the hydrogels. Cell encapsulated hydrogels were prepared by mixing cells into a 
a

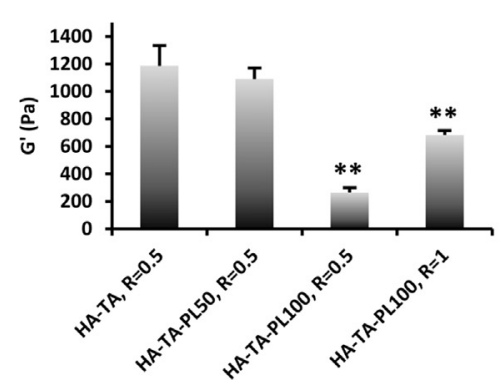

b

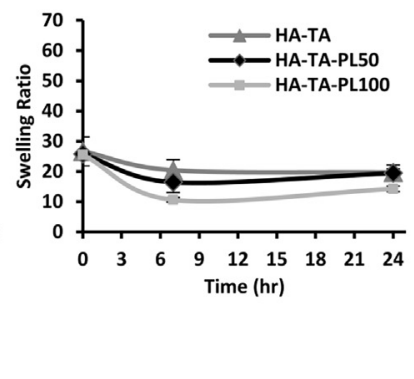

C

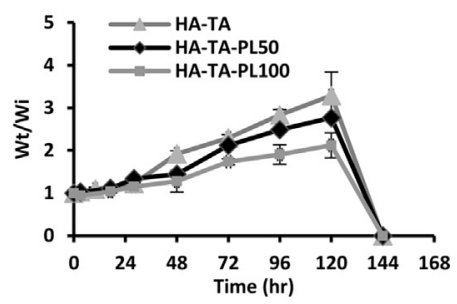

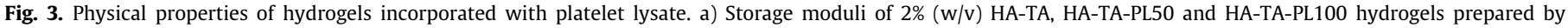

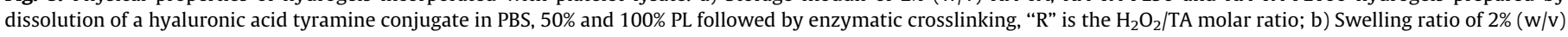

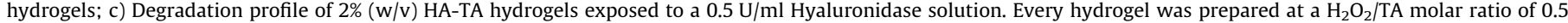
except for the HA-TA-PL100 which was 1 , and mgHRP/mmolTA ratio of 0.2 .

polymer solution containing HRP and subsequent addition of a polymer solution containing $\mathrm{H}_{2} \mathrm{O}_{2}$. At different time points, phase contrast microscopy as well as F-Actin and Dapi staining were performed to observe the morphology of encapsulated cells. As shown in Fig. 4, cells maintained their spherical morphology when encapsulated in a HA-TA hydrogel. In contrast, cells encapsulated in HATA-PL50 and HA-TA-PL100 hydrogels attached to the matrix and continued spreading over time. These effects were more pronounced for the HA-TA-PL100 hydrogels in which cells form an interconnected network. However, in the HA-TA-PL50 hydrogel the attached cells did not spread to a similar extend like in HATA-PL100 hydrogels and retained a more spherical morphology.

\subsection{Viability and proliferation of encapsulated cells}

The viability of the hMSCs in the hydrogels was determined using a Live/Dead staining (Fig. S2). The staining showed high cell viabilities (>95\%) in all samples at day 7 and 14 . The spreading of the cells having a spindle like morphology in PL enriched hydrogels was also clear from a Calcein-AM staining. The metabolic activity of the cells was determined by a Prestoblue assay. As shown in Fig. 5a, the use of PL in hydrogel constructs (HA-TA-PL50 and HA-TA-PL100) significantly increased the activity of the encapsulated hMSCs, while for the HA-TA hydrogel a decrease was observed. A CyQuant DNA assay was used to evaluate the proliferation of the hMSCs in the hydrogels up to day 14 (Fig. 5b). In HA-TA hydrogels the DNA amount decreased significantly after one day and then remained constant which could be related to escape of the cells from the hydrogel. However, in a HA-TA-PL100 construct, the DNA content increased 1.5-fold from day 1 to day 7 , which is in line with the increased metabolic activity. From day 7 to day 14 no further changes were observed. For the HA-TA-PL50 hydrogel, the DNA content initially decreased, but after 3 days started to increase. After 2 weeks of culture, the DNA amount in PL loaded hydrogels was much higher than in the HA-TA hydrogel. The metabolic activity corrected for the DNA content of each construct as presented in Fig. 5c was significantly higher after three days of culture for the HA-TA-PL50 and HA-TA-PL100 than HA-TA constructs.
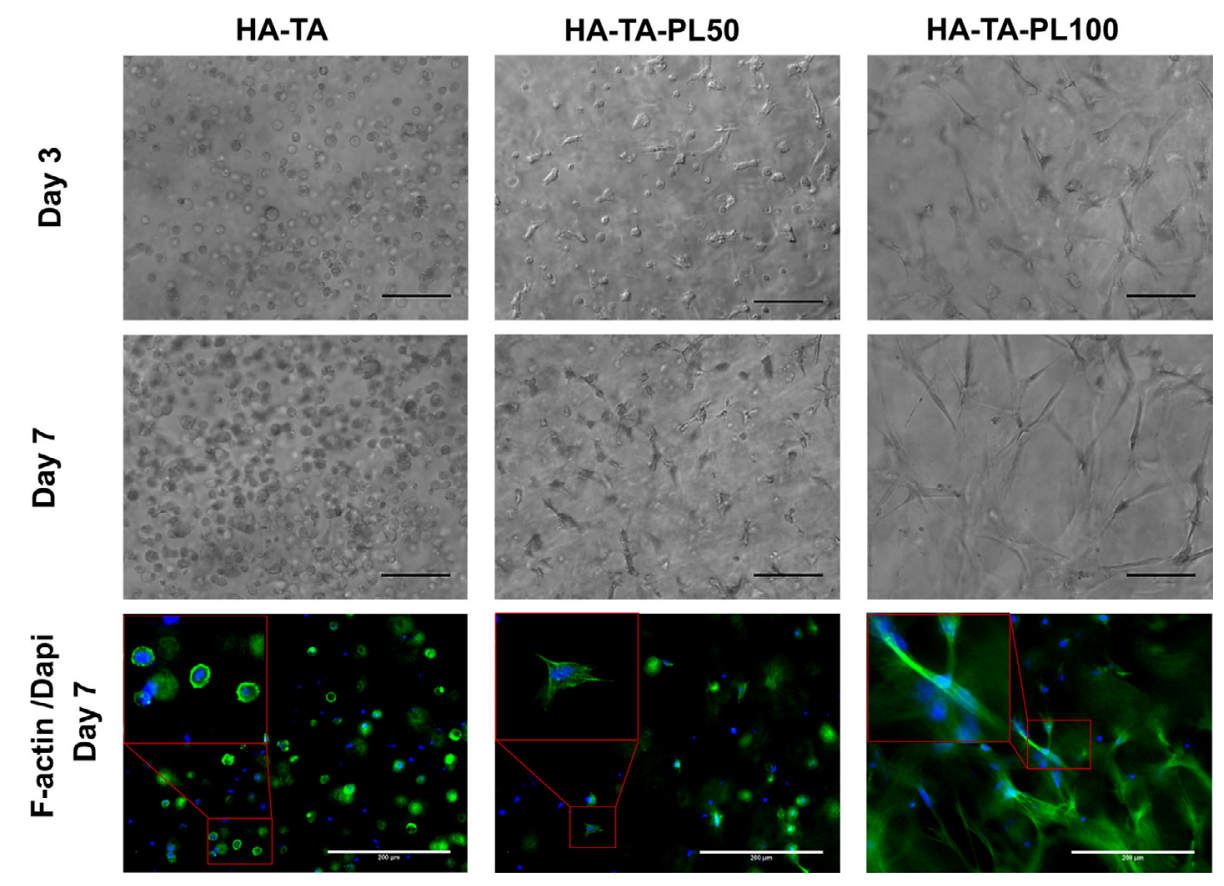

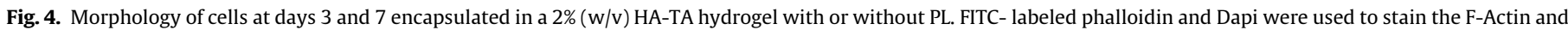

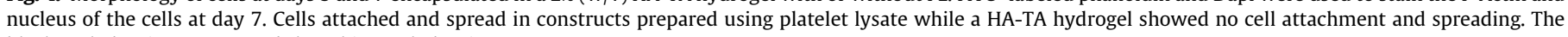
black scale bar is $100 \mu \mathrm{m}$, and the white scale bar is $200 \mu \mathrm{m}$. 

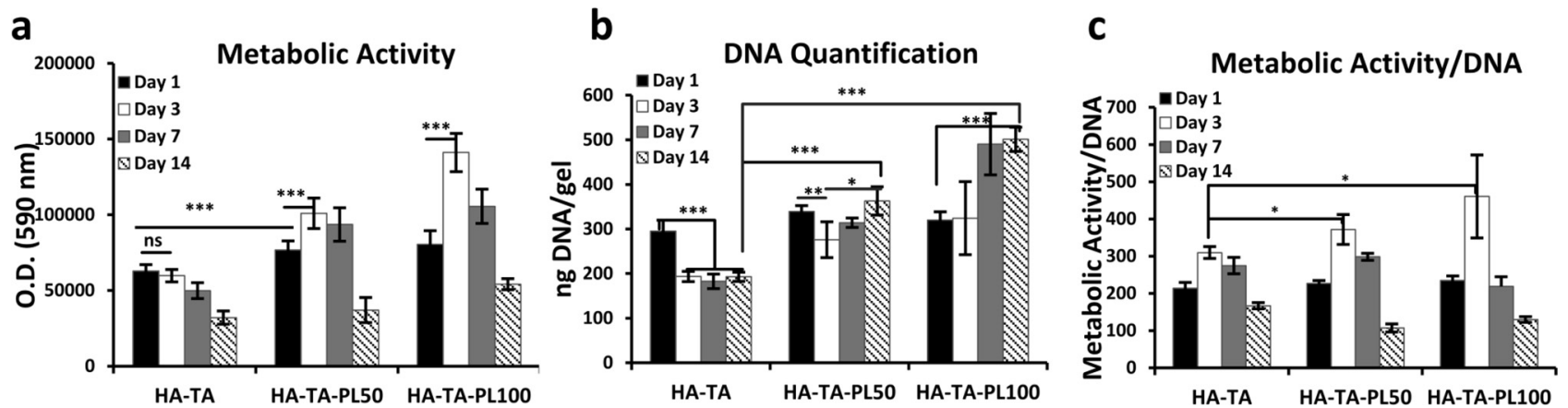

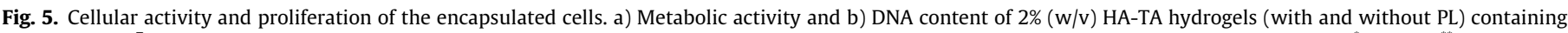

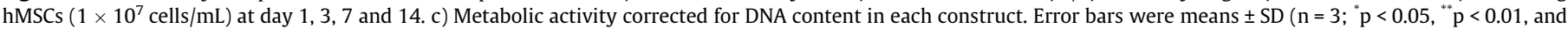
p $<0.001$; ns: not significant).

The results showed that, the cellular growth is supported by bothHA-TA-PL100 and HA-TA-PL50 hydrogels while inhibited by HA-TA construct.

\subsection{Chondrogenic induction}

hMSCs laden hydrogels in the presence or absence of the platelet lysate were cultured in chondrogenic induction medium. The morphology of the cells during differentiation was visualized with phase contrast microscopy (Fig. 6). In the absence of PL, the cells remained round similarly as in expansion medium (Fig. 4). However, encapsulated hMSCs in PL loaded hydrogels, especially for the HA-TA-PL100 construct, maintained a more round and chondrocyte-like shape in contrast to the spindle cell shape in normal culture medium. F-actin/Dapi staining was performed to visualize the cell morphology inside the PL enriched hydrogels after 28 days differentiation (Fig. 6a). The HA-TA hydrogel was completely degraded after 4 weeks. Clearly, the cells in the
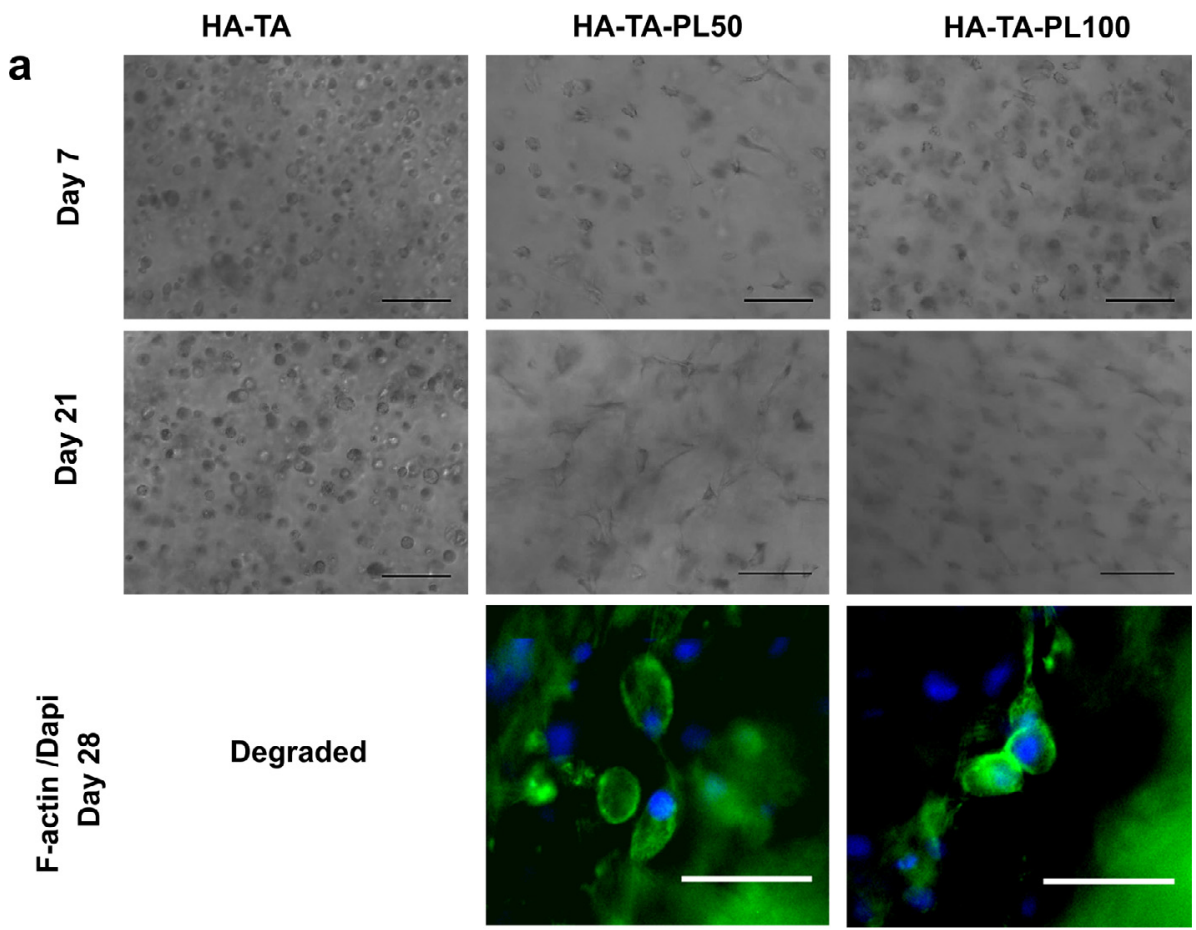

b

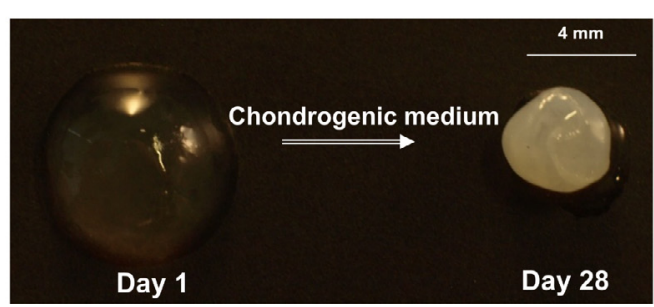

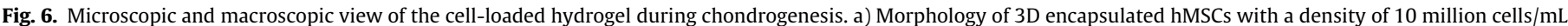

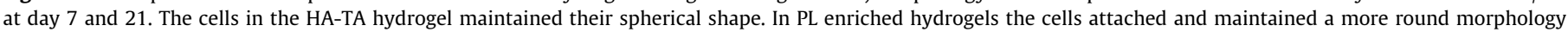

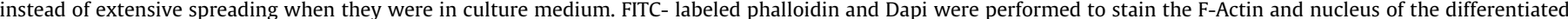

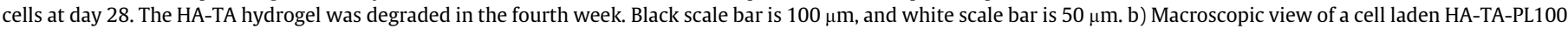
hydrogel at day 1 and 28 after culturing in chondrogenic medium. 

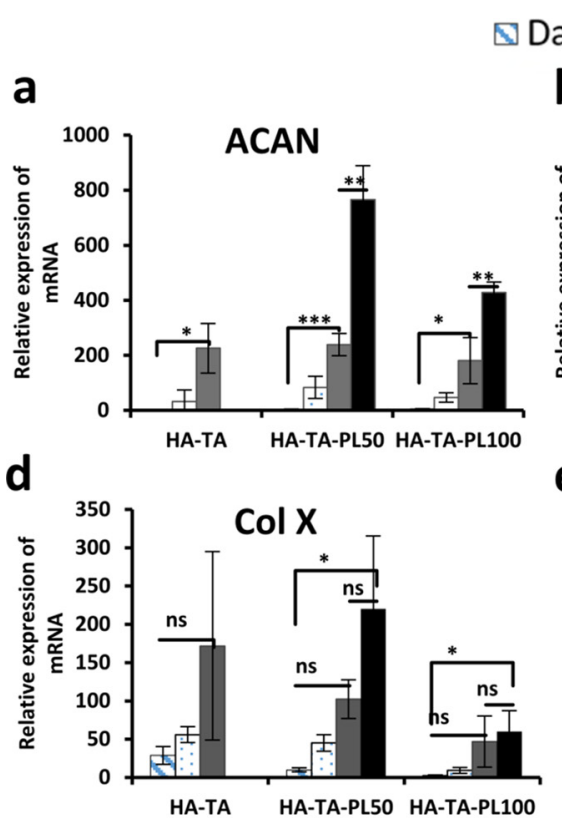

@Day $7 \square$ Day 14

b

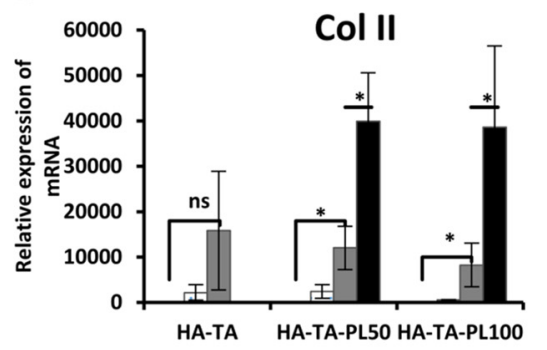

e

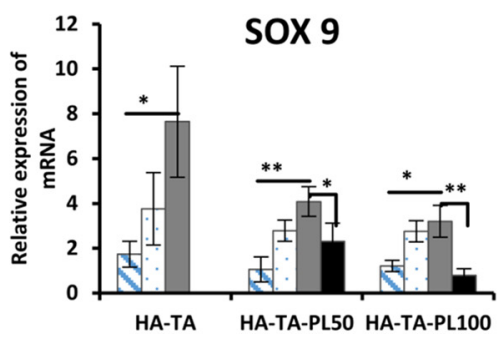

Day 35

C

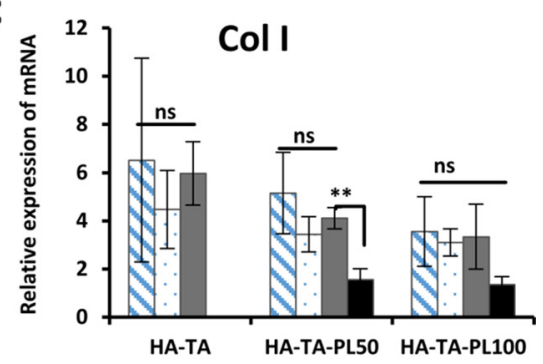

f

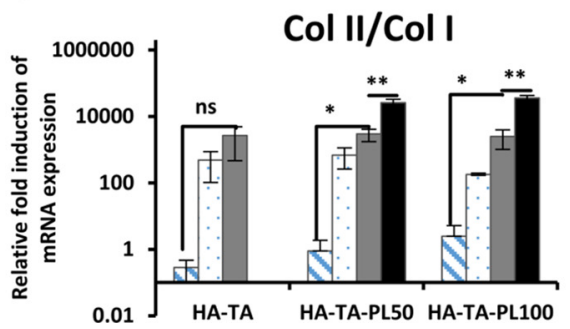

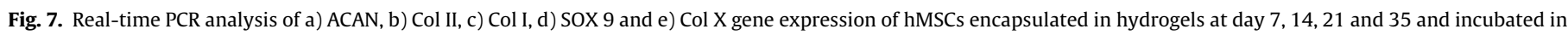

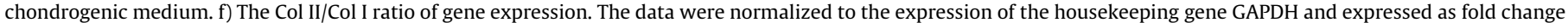

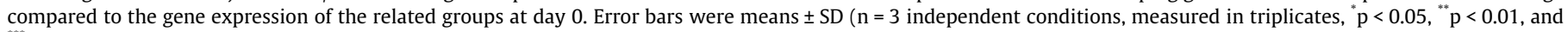
${ }^{* * *} \mathrm{p}<0.001$; ns: not significant).

HA-TA-PLA50 and HA-TA-PLA100 have a chondrocyte-like morphology in the $3 \mathrm{D}$ environment. The macrostructure of the HA-TA-PL100 hydrogel at days 1 and 28 of differentiation is presented in Fig. $6 \mathrm{~b}$. The initially transparent hydrogel became a very tough and opaque structure with smaller size. For HA-TA-PL50 a similar tough construct was produced after 4 weeks (not shown).

\subsection{Gene expression}

For all hMSCs incorporated hydrogels in the presence or absence of PL, and at different time points (day 7, 14, 21 and 35), the expression of the chondrogenic related genes ACAN, Col II, and Sox 9, and also the expression of $\mathrm{Col} \mathrm{I}$ and $\mathrm{Col} \mathrm{X}$ were evaluated by real-time PCR (RT-PCR) (Fig. 7). Because the HA-TA hydrogel was degraded after 3 weeks no data are available for day 35 of this hydrogel. The expression of Col II for both HA-TA-PL50 and HA-TAPL100 is much higher than for the HA-TA hydrogel which indicates a positive effect of PL in up-regulation of this important cartilage marker. No significant differences in expression of Col II observed for the HA-TA hydrogel over time. Importantly, the HA-TA, HATA-PL50 and HA-TA-PL100 hydrogels did not indicate significant decrease or increase in the expression level of Col I, a main component of fibrous cartilage, and also Col X up to day 21. For the HATA-PL50 construct, the Col I expression was down regulated after 3 weeks. However, for both PL loaded constructs the expression of Col X at day 35 was significantly higher than at day 7 (pvalue $=0.02$ ). There is an increase in the ACAN mRNA level for all types of hydrogels over time in culture. The expression of SOX 9, as a major chondrogenic regulator, increased and maximized at day 21 for all hydrogels and then it started to decrease for PL enriched constructs. As shown in Fig. $7 \mathrm{f}$ the ratio of $\mathrm{Col} \mathrm{II} / \mathrm{Col} \mathrm{I}$ in PL loaded hydrogels was improved and became pronounced during culture while did not change significantly in HA-TA construct.

\subsection{Histological analysis and immunohistochemistry}

The accumulation of a chondrogenic specific ECM in the hydrogel/cell constructs was examined by histological analysis.
For visualizing glycosaminoglycans and proteoglycans in a cartilage-like extracellular matrix, Alcian blue and Safranin $O$ staining were performed (Fig. 8). As the hyaluronic acid is a GAG, it gives a positive staining for both Alcian blue and Safranin O. At day 1 the stained sections show a highly porous structure of the cell-laden HA-TA hydrogel (Fig. 8a,d), which remains similar at day 7 (data not shown). At day 28, the HA-TA hydrogel is fully degraded and no sample could be retrieved. For PL containing hydrogels the staining at day 1 is similar as for the HA-TA hydrogel (data not shown). Interestingly, in PL loaded hydrogels, after 4 weeks of culture in chondrogenic medium (Fig. 8b,c,e,f), the pores are almost absent, cells are rounded and reside within lacunae. Also, in HA-TA-PL50 and HA-TA-PL100 constructs the intensity of the stained areas are not the same everywhere, and stronger stained zones are visible which may show the deposition of newly produced GAGs. Another possibility of the observed higher stained areas is the local shrinkage of the hydrogel through chondrogenesis which makes these areas denser. As it was shown in Fig. 6b, the HA-TA-PL100 samples were remodeled into tough and cartilage-like constructs during chondrogenesis. At day 35, after fixation with $10 \%$ formalin, the samples were treated with $200 \mathrm{U} / \mathrm{ml}$ HAase for 2 days to digest all hyaluronic acid and dissolute the proteoglycans present. Alcian blue/Fast red and Safranin O/ Hematoxylin staining were performed on the sections of HA-TAPL100 before and after HAase treatment, and the results are shown in Fig. 8g,h, and Fig. 8i,j, respectively. Images show that enzymatic digestion of the hyaluronic acid, which can be initially present or newly deposited HA and attached proteoglycans, leaves a matrix with cells. The cells nuclei were stained with Fast red and Hematoxylin. Also, the macroscopic appearance of the construct before and after treatment with HAase did not change as it was shown in Fig. 8g,h. This shows that the cells definitely had produced new matrix and they were embedded in their ECM.

The production of collagen types II and I in the final construct was visualized by immunohistochemistry using a specific human Col II and I binding antibody (Fig. 9a-f). The Collagens stained brown and the nuclei counter stained purple. Highly dense cell areas can be observed. The cells are surrounded by collagen II 

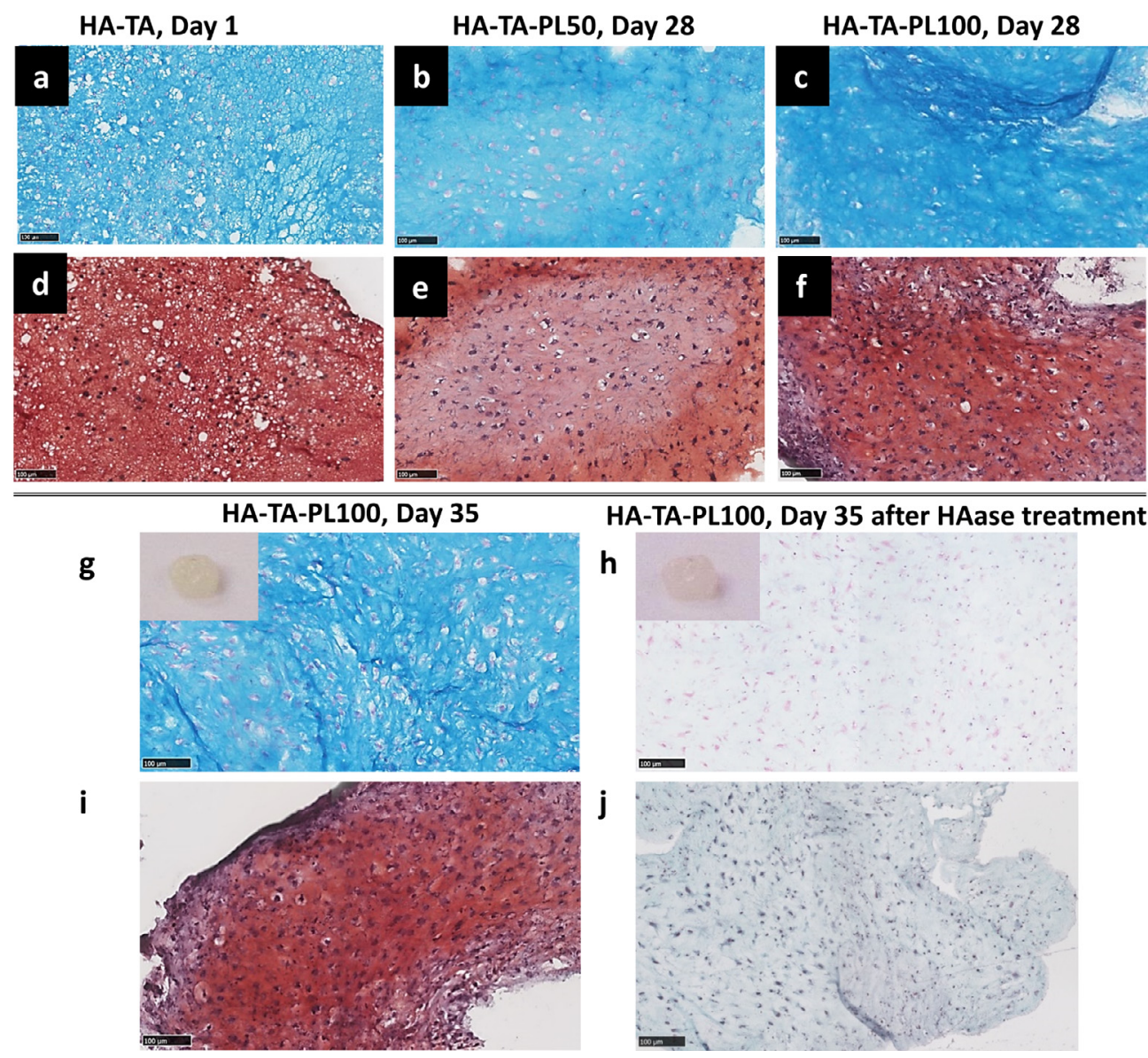

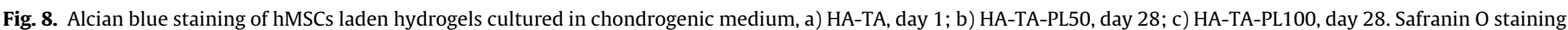
of hydrogels cultured in chondrogenic medium, d) HA-TA, day 1; e) HA-TA-PL50, day 28; f) HA-TA-PL100, day 28. After four weeks, the cells have a chondrocyte-like morphology and reside within lacunae. g, h) Macroscopic appearance and Alcian blue staining of HA-TA-PL100 construct at day 35 before and after treatment with $200 \mathrm{U} / \mathrm{ml}$ Hyaluronidase. i, j) Safranin O staining of HA-TA-PL100 construct at day 35 before and after treatment with $200 \mathrm{U} / \mathrm{ml}$ Hyaluronidase. Scale bar is $100 \mu \mathrm{m}$. (For interpretation of the references to colour in this figure legend, the reader is referred to the web version of this article.)
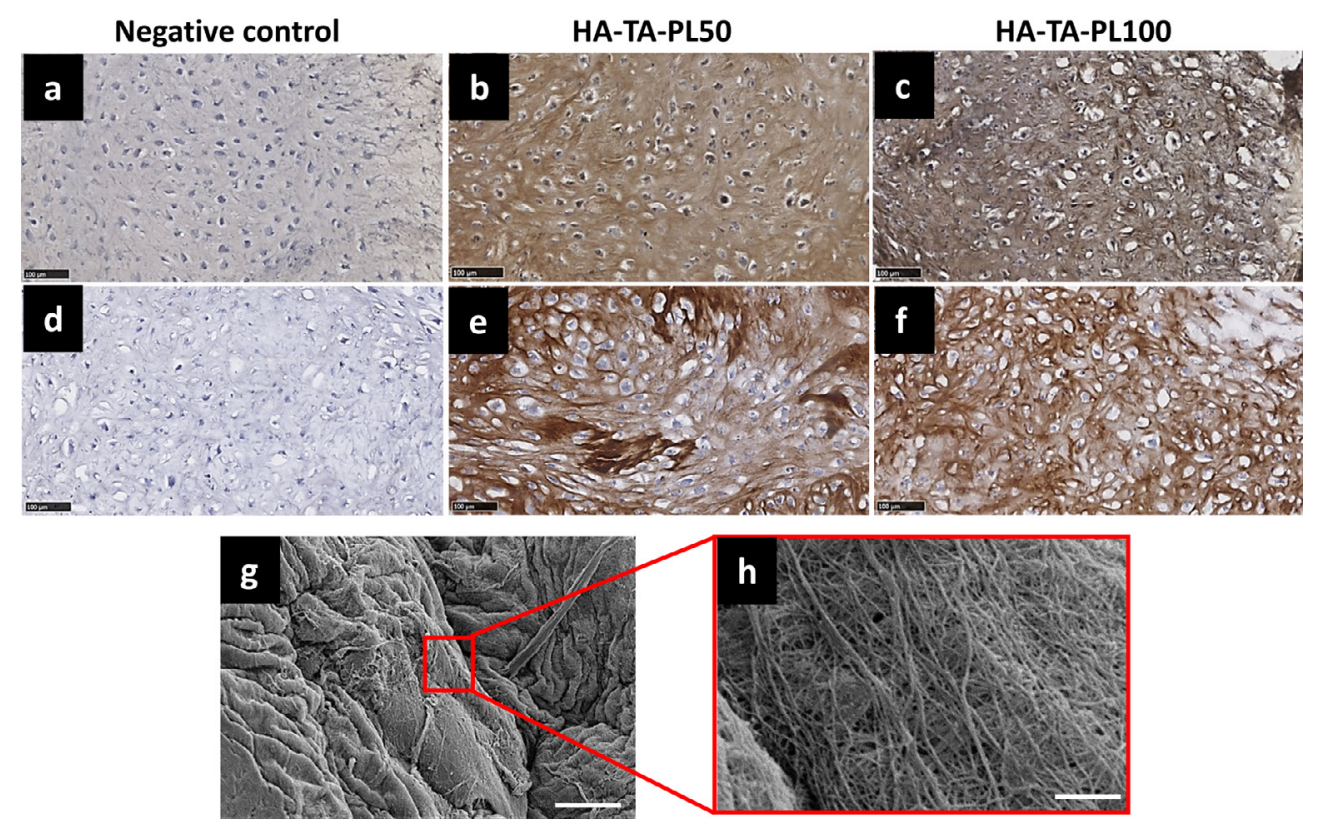

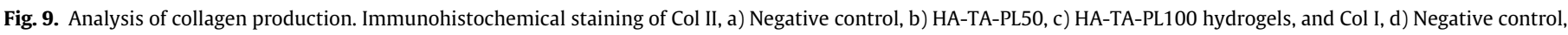

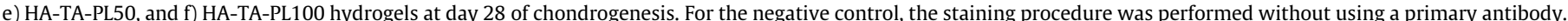

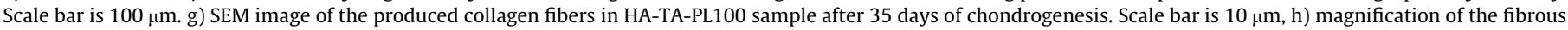
matrix, scale bars are $1 \mu \mathrm{m}$. 
and I mimicking the production of a cartilage like tissue. The deposition of the collagen fibers was confirmed by SEM analysis of a HA-TA-PL100 hydrogel (Fig. 9g,h).

\section{Discussion}

Nowadays Platelet-rich blood derivatives like platelet rich plasma (PRP) and platelet rich fibrin (PRF) are studied for their use in regenerative medicine. Both PRP and PRF have a high concentration of platelets that release growth factors and bioactive proteins that may initiate and accelerate tissue repair and regeneration [52]. The effects of using this autologous blood product on regeneration of bone, cartilage, tendon and skin have been discussed in several studies [52-55]. However, the effectiveness of PRP in clinical uses has shown some limitations which may be related to the variability in the PRP composition between different donors [56-58]. Age, sex, and patient comorbidities affect the composition of this blood derivative. In addition to the intra-patient variation, there is no standardized protocol for the preparation of PRP which can lead to inconsistent clinical results [59]. Moreover, it is not well studied how these variations will affect stem cell behavior and regeneration in vivo [36,60]. A drawback of PRF gels is their low mechanical properties and fast degradation that hamper application in load bearing regions, such as joints [52]. Growth factors are very fast released from platelets and have a short halflife hampering their effectiveness for the longer time periods needed for tissue repair [61]. Platelet lysate, as a protein rich solution, represents a new and exciting opportunity for tissue engineering. PL contains structural constituents of the ECM such as thrombospondin, vitronectin, and fibronectin which enhances cell adhesion and interaction between cells [62]. Combining PL with biomaterials to maintain the beneficial effects of PL over a longer period of time is an approach that received attention more recently $[29,37,63]$. The commercial PL used in this study was obtained from several human platelet batches, containing over $2 * 10^{11}$ platelets according the manufacturer. The platelets were pooled to decrease batch to batch variation and exposed to three repeated freeze-thaw cycles to lyse the platelets. After centrifugation to remove cell debris, the supernatant was filtered.

Combining the advantageous properties of platelet lysate with in situ forming hyaluronic acid tyramine conjugate hydrogels by enzymatic crosslinking can provide injectable hydrogels that boost tissue regeneration. HA was chosen since it is a biocompatible and biodegradable material and constituting one of the main components of the cartilage. Furthermore, it is a negatively charged polymer which enables electrostatic interaction with positively charged growth factors like FGF-2 ( $\mathrm{pI}=9.6), \mathrm{VEGF}(\mathrm{pI}=8.5$ ), and TGF- $\beta 1$ ( $\mathrm{pI}=8.83$ ) present in PL. Gels formed by dissolving the polymer in PBS or PL, and subsequent addition of HRP and $\mathrm{H}_{2} \mathrm{O}_{2}$, had a similar swelling and degradation behavior. The mechanical properties of a hydrogel prepared using pure platelet lysate as a medium (HA-TA-PL100) appeared lower than a similar hydrogel prepared using PBS (Fig. 3a). This is likely due to the presence of catalase in the platelet lysate. Catalase is known to decompose $\mathrm{H}_{2} \mathrm{O}_{2}$, thereby preventing complete crosslinking. Using a two-fold higher amount of $\mathrm{H}_{2} \mathrm{O}_{2}$ compensated the effect of hydrogen peroxide decomposition and increased the storage modulus to a value comparable to crosslinking using PBS as a medium.

In human mesenchymal stem cell (hMSC) laden hydrogels the presence of PL had a clear impact on cell morphology and cellular function like spreading and proliferation (Fig. 4). While cells in HATA hydrogel were round, cells in PL containing gels showed a more spindle shape like morphology. This effect was strongest in HA-TAPL100 gels in which cells form an interconnecting network. The change in morphology is likely due to the presence of fibrinogen, fibronectin and vitronectin in PL which enable cell attachment, spreading and migration [64-66]. Integrin binding happens via the arginine-glycine-aspartic acid (RGD) sequence present in these proteins [67]. Additionally, the presence of some growth factors like Platelet-derived growth factor (PDGF) which is abundant in PL may contribute to cell adhesion [68]. Although, hyaluronic acid itself interacts with cells via CD44, a cell membrane adhesion receptor [69], it is unable to serve as substrate for key adhesion receptors such as integrins [70,71]. The HA-TA-PL100 hydrogel allowed extensive cell spreading, while the HA-TA-PL50 showed an intermediate behavior (Fig. 4). The higher amount of proteins present in HA-TA-PL100 likely provides more cell adhesion sites. Another reason may be related to the lower crosslink density of the HA-TA-PL100 hydrogel. As mentioned before, the catalase, which is present in PL, decomposes the $\mathrm{H}_{2} \mathrm{O}_{2}$ molecules, resulting in a less crosslinked network. Moreover, decreasing the HA concentration from $2 \%(\mathrm{w} / \mathrm{v})$ to $1 \%(\mathrm{w} / \mathrm{v})$ in HA-TA-PL100 constructs, while keeping the crosslinking density constant $\left(\mathrm{H}_{2} \mathrm{O}_{2} / \mathrm{TA}\right.$ molar ratio equal to 0.5 ), increased the rate of cell spreading (Fig. S3). The storage modulus of the 1 and 2\% (w/v) HA-TA hydrogels is 439 and $1250 \mathrm{~Pa}$, respectively, which is considered a soft gel. As it was shown in Fig. S3, initial cell attachment and spreading process happened faster in $1 \%(\mathrm{w} / \mathrm{v})$ hydrogel compared to the $2 \%(\mathrm{w} / \mathrm{v})$ hydrogel. This inverse relationship between stiffness and cell spreading was also shown previously by Yuguo and coworkers [70].

A Live/Dead and Presto blue assay revealed encapsulated hMSCs were alive and metabolically active during culture (Figs. S3 and 5a). However, the metabolic activity of the encapsulated cells in HA-TA constructs tends to decrease over time. PL appears to have a vital role in the enhancement of the cell metabolic activity. The presence of a multitude of entrapped growth factors in HA-TA-PL hydrogels may promote cell metabolic activity especially in the early stages. For the HA-TA-PL50, the initial decrease in DNA content could result from the escape of cells from the construct, but increased in the following weeks showing cellular proliferation. Higher cellular growth was observed in HA-TA-PL100 gels compared to HA-TA-PL50 gels which shows that the hMSCs interact to a higher extend with the HA-TA-PL100. The presence of more binding sites in HA-TA-PL100, as a result of higher PL concentration, could facilitate cell spreading and thus induce an increase in cell proliferation.

The ability of encapsulated hMSCs in HA-TA, HA-TA-PL50 and HA-TA-PL100 hydrogels to undergo chondrogenesis when incubated in chondrogenic medium was investigated. Unlike the stretched form of the hMSCs in a HA-TA-PL100 hydrogel incubated in culture medium, the cells do not elongate when the construct was incubated in chondrogenic medium (Fig. 6). The upregulation of collagen type II and the down-regulation of collagen type I gene expression in PL loaded hydrogels shows that PL leads hMSCs differentiation towards a hyaline cartilage lineage. Based on immunohistochemistry study showing collagen type II and type I formation (Fig. 9a-f) chondrogenesis takes place throughout the construct and all cells are completely embedded between collagen fibers. The chondrocytic morphology of the cells in the construct can be observed for both HA-TA-PL50 and HA-TA-PL100. Also, the area covered by collagen fibers appears the same for both PL containing hydrogels. It can be concluded that although the concentration of PL has a vital role in spreading, metabolic activity and thus proliferation of the cells encapsulated in the 3D hydrogel during culture in expansion medium, it may not have a significant effect on cell chondrogenesis. Both HA-TA-PL50 and HA-TA-PL100 support MSCs differentiation, and finally they will be remodeled to a cartilaginous construct.

Chondrogenesis of mesenchymal stem cells in hyaluronic acid hydrogels has been addressed in a few studies. Toh et al. described the effect of the degree of crosslinking of hyaluronic acid hydrogel on the chondrogenesis of MSCs and found that soft matrices 
enhanced chondrogenesis and hyaline cartilage formation [30]. With increasing hydrogel stiffness cells were more elongated and differentiated towards a fibrous phenotype and fibrous tissue was produced. In the present study it was observed that cells can spread and elongate in the HA-TA-PL100 construct and differentiate to chondrocytes and produced abundant collagen type II, revealing that cell adhesion also plays a role in chondrogenesis. In another paper, Bian et al. described a methacrylated HA hydrogel prepared via photocrosslinking and investigated the effect of crosslinking density on the hypertrophic differentiation of encapsulated MSCs [72]. For softer hydrogels with Young's moduli below $10 \mathrm{kPa}$, a lower expression of collagen type X, a hypertrophic marker, was reported. However, UV-mediated crosslinking may compromise the biocompatibility of the hydrogel and have negative effects on encapsulated cells.

After cell encapsulation in the hydrogel the structure of the hydrogel will change. As shown in Fig. S4, a HA-TA-PL hydrogel without cells has a highly porous network, while the cell-laden construct appeared denser. The structure of HA-TA-PL100 at day 28 (Fig. S4) after chondrogenesis revealed the absence of macro pores and cells embedded in a new matrix.

When the hydrogels were put in chondrogenic medium allowing cells to undergo chondrogenic differentiation, remodeling occurred for all samples (Fig. S5). At day 14, the diameter of the HA-TA, HATA-PL50 and HA-TA-PL100 reduced to $92 \pm 2 \%, 95 \pm 3 \%$ and $74 \pm 2 \%$ of the original diameter, respectively. In the following week the HA-TA hydrogel started to swell and was completely degraded at week four, while the HA-TA-PL50 and HA-TA-PL100 constructs continued remodeling to $81 \pm 4 \%$ and $58 \pm 3 \%$ of the initial hydrogel diameter. The contraction is simultaneous with accumulation of newly deposited matrix. In addition, degradability of hydrogel is also considered to be essential to deposit matrix components toward the formation of functional tissue structures. In PL loaded constructs the formation of the new matrix by the cells and the degradation of the original network appear to occur at the same pace. In both constructs, the cells underwent chondrogenesis and they produced extracellular matrix as shown in Fig. 9. By using $50 \% \mathrm{v} / \mathrm{v}$ of PL as a medium in the preparation of hydrogels, ECM production appears more favorable because of the largely retained volume of the newly formed matrix compared to the starting gel volume.

\section{Conclusion}

In this study, an enzymatically crosslinked HA-TA hydrogel was complemented by incorporation of platelet lysate as an autologous source of growth factors and stimuli. Our data shows that injectable HA-TA hydrogel loaded with platelet lysate is an easy-to-apply approach and can be used for cell delivery purposes. The platelet lysate provides biological cues to cell hydrogel constructs rendering it a proper substrate for cell attachment and growth. The mild gelation condition of this in situ forming hydrogel allows retention of the cells and platelet lysate in the hydrogel at the defect site. The ability of platelet lysate to stimulate chondrogenesis of mesenchymal stem cells encapsulated in hyaluronic acid hydrogels is expected to provide a viable treatment to address cartilage defects. Although the result of using PL loaded hydrogel for cartilage defect repair are encouraging, the exact amounts of the bioactive molecules present in the hydrogel and the ratios between them should be determined in order to achieve the desired effect in vivo.

\section{Acknowledgments}

This project has received funding from the European Union's Horizon 2020 research and innovation program under grant agreement
No 691128, Iranian National Science Foundation (INSF) under grant number 94004082, and Iran's National Elites Foundation (INEF). The authors also thank Dr. Jeroen Leijten, of the University of Twente, for valuable discussions.

\section{Conflict of interest}

The authors declare no conflict of interest.

\section{Appendix A. Supplementary data}

Supplementary data to this article can be found online at https://doi.org/10.1016/j.actbio.2018.10.031.

\section{References}

[1] T.J. Klein, J. Malda, R.L. Sah, D.W. Hutmacher, Tissue engineering of articular cartilage with biomimetic zones, Tissue Eng.Part B: Rev. 15 (2) (2009) 143157.

[2] L. Kock, C.C. van Donkelaar, K. Ito, Tissue engineering of functional articular cartilage: the current status, Cell Tissue Res. 347 (3) (2012) 613-627.

[3] T. Karimi, D. Barati, O. Karaman, S. Moeinzadeh, E. Jabbari, A developmentally inspired combined mechanical and biochemical signaling approach on zonal lineage commitment of mesenchymal stem cells in articular cartilage regeneration, Integr. Biol. 7 (1) (2015) 112-127.

[4] J.L. Drury, D.J. Mooney, Hydrogels for tissue engineering: scaffold design variables and applications, Biomaterials 24 (24) (2003) 4337-4351.

[5] J.K. Tessmar, A.M. Göpferich, Matrices and scaffolds for protein delivery in tissue engineering, Adv. Drug Deliv. Rev. 59 (4) (2007) 274-291.

[6] S.R. Frenkel, P.E. Di Cesare, Scaffolds for articular cartilage repair, Ann. Biomed. Eng. 32 (1) (2004) 26-34.

[7] J.D. Kretlow, L. Klouda, A.G. Mikos, Injectable matrices and scaffolds for drug delivery in tissue engineering, Adv. Drug Deliv. Rev. 59 (4) (2007) 263-273.

[8] S.R. Van Tomme, G. Storm, W.E. Hennink, In situ gelling hydrogels for pharmaceutical and biomedical applications, Int. J. Pharm. 355 (1) (2008) 118.

[9] A. Hatefi, B. Amsden, Biodegradable injectable in situ forming drug delivery systems, J. Control. Release 80 (1-3) (2002) 9-28.

[10] K.H. Bae, L.-S. Wang, M. Kurisawa, Injectable biodegradable hydrogels: progress and challenges, J. Mater. Chem. B 1 (40) (2013) 5371-5388.

[11] P.B. Malafaya, G.A. Silva, R.L. Reis, Natural-origin polymers as carriers and scaffolds for biomolecules and cell delivery in tissue engineering applications, Adv. Drug Deliv. Rev. 59 (4) (2007) 207-233.

[12] C. Chung, J.A. Burdick, Engineering cartilage tissue, Adv. Drug Deliv. Rev. 60 (2) (2008) 243-262.

[13] E. Arslan, M.S. Ekiz, C.E. Cimenci, N. Can, M.H. Gemci, H. Ozkan, M.O. Guler, A.B. Tekinay, Protective therapeutic effects of peptide nanofiber and hyaluronic acid hybrid membrane in in vivo osteoarthritis model, Acta Biomater. 73 (2018) 263-274

[14] K. Kawasaki, M. Ochi, Y. Uchio, N. Adachi, M. Matsusaki, Hyaluronic acid enhances proliferation and chondroitin sulfate synthesis in cultured chondrocytes embedded in collagen gels, J. Cell. Physiol. 179 (2) (1999) $142-$ 148.

[15] M. Akmal, A. Singh, A. Anand, A. Kesani, N. Aslam, A. Goodship, G. Bentley, The effects of hyaluronic acid on articular chondrocytes, Bone Joint J. 87 (8) (2005) 1143-1149.

[16] K. Haberstroh, A. Enz, M. Zenclussen, A. Hegewald, K. Neumann, A. Abbushi, C. Thomé, M. Sittinger, M. Endres, C. Kaps, Human intervertebral disc-derived cells are recruited by human serum and form nucleus pulposus-like tissue upon stimulation with TGF- $\beta 3$ or hyaluronan in vitro, Tissue Cell 41 (6) (2009) 414-420.

[17] A. Aruffo, I. Stamenkovic, M. Melnick, C.B. Underhill, B. Seed, CD44 is the principal cell surface receptor for hyaluronate, Cell 61 (7) (1990) 1303-1313.

[18] L. Sherman, J. Sleeman, P. Herrlich, H. Ponta, Hyaluronate receptors: key players in growth, differentiation, migration and tumor progression, Curr. Opin. Cell Biol. 6 (5) (1994) 726-733.

[19] C.E. Schanté, G. Zuber, C. Herlin, T.F. Vandamme, Chemical modifications of hyaluronic acid for the synthesis of derivatives for a broad range of biomedical applications, Carbohydr. Polym. 85 (3) (2011) 469-489.

[20] L. Kenne, S. Gohil, E.M. Nilsson, A. Karlsson, D. Ericsson, A.H. Kenne, L.I. Nord, Modification and cross-linking parameters in hyaluronic acid hydrogelsdefinitions and analytical methods, Carbohydr. Polym. 91 (1) (2013) 410-418.

[21] M.N. Collins, C. Birkinshaw, Hyaluronic acid based scaffolds for tissue engineering-a review, Carbohydr. Polym. 92 (2) (2013) 1262-1279.

[22] S.J. Sofia, A. Singh, D.L. Kaplan, Peroxidase-catalyzed crosslinking of functionalized polyaspartic acid polymers, J. Macromol. Sci., Part A 39 (10) (2002) 1151-1181.

[23] F. Lee, J.E. Chung, M. Kurisawa, An injectable enzymatically crosslinked hyaluronic acid-tyramine hydrogel system with independent tuning of mechanical strength and gelation rate, Soft Matter 4 (4) (2008) 880-887. 
[24] M. Nakahata, E. Gantumur, K. Furuno, S. Sakai, M. Taya, Versatility of hydrogelation by dual-enzymatic reactions with oxidases and peroxidase, Biochem. Eng. J. (2017).

[25] R. Jin, L.M. Teixeira, P. Dijkstra, C. Van Blitterswijk, M. Karperien, J. Feijen, Enzymatically-crosslinked injectable hydrogels based on biomimetic dextranhyaluronic acid conjugates for cartilage tissue engineering, Biomaterials 31 (11) (2010) 3103-3113.

[26] R. Jin, L.S. Moreira Teixeira, P.J. Dijkstra, Z. Zhong, C.A. van Blitterswijk, M. Karperien, J. Feijen, Enzymatically crosslinked dextran-tyramine hydrogels as injectable scaffolds for cartilage tissue engineering, Tissue Eng. Part A 16 (8) (2010) 2429-2440.

[27] B.V. Slaughter, S.S. Khurshid, O.Z. Fisher, A. Khademhosseini, N.A. Peppas, Hydrogels in regenerative medicine, Adv. Mater. 21 (32-33) (2009) $3307-$ 3329.

[28] L. Cai, R.E. Dewi, S.C. Heilshorn, Injectable hydrogels with in situ double network formation enhance retention of transplanted stem cells, Adv. Funct. Mater. 25 (9) (2015) 1344-1351.

[29] L.S. Neves, P.S. Babo, A.I. Gonçalves, R. Costa-Almeida, S.G. Caridade, J.F. Mano, R.M. Domingues, M.T. Rodrigues, R.L. Reis, M.E. Gomes, Injectable hyaluronic acid hydrogels enriched with platelet lysate as a cryostable off-the-shelf system for cell-based therapies, Regener. Eng. Transl. Med. 3 (2) (2017) 53-69.

[30] W.S. Toh, T.C. Lim, M. Kurisawa, M. Spector, Modulation of mesenchymal stem cell chondrogenesis in a tunable hyaluronic acid hydrogel microenvironment, Biomaterials 33 (15) (2012) 3835-3845.

[31] S.U. Kim, J. De Vellis, Stem cell-based cell therapy in neurological diseases: a review, J. Neurosci. Res. 87 (10) (2009) 2183-2200.

[32] I.L. Weissman, Stem cells: units of development, units of regeneration, and units in evolution, Cell 100 (1) (2000) 157-168.

[33] C. Cha, W.B. Liechty, A. Khademhosseini, N.A. Peppas, Designing biomaterials to direct stem cell fate, ACS Nano 6 (11) (2012) 9353-9358.

[34] R.J. do Amaral, A. Matsiko, M.R. Tomazette, W.K. Rocha, E. Cordeiro-Spinetti, T. J. Levingstone, M. Farina, F.J. O’Brien, M.C. El-Cheikh, A. Balduino, Platelet-rich plasma releasate differently stimulates cellular commitment toward the chondrogenic lineage according to concentration, J. Tissue Eng. 6 (2015) 1-14.

[35] J. Krüger, A. Ketzmar, M. Endres, A. Pruss, A. Siclari, C. Kaps, Human, plateletrich plasma induces chondrogenic differentiation of subchondral progenitor cells in polyglycolic acid-hyaluronan scaffolds, J. Biomed. Mater. Res.Part B, Appl. Biomater. 102 (4) (2014) 681.

[36] E.A. Masoudi, J. Ribas, G. Kaushik, J. Leijten, A. Khademhosseini, Platelet-rich blood derivatives for stem cell-based tissue engineering and regeneration, Curr. Stem Cell Rep. 2 (1) (2016) 33-42.

[37] L.S.M. Teixeira, J.C. Leijten, J.W. Wennink, A.G. Chatterjea, J. Feijen, C.A. van Blitterswijk, P.J. Dijkstra, M. Karperien, The effect of platelet lysate supplementation of a dextran-based hydrogel on cartilage formation, Biomaterials 33 (14) (2012) 3651-3661.

[38] M.R. De Pascale, L. Sommese, A. Casamassimi, C. Napoli, Platelet derivatives in regenerative medicine: an update, Transfus. Med. Rev. 29 (1) (2015) 52-61.

[39] V.E. Santo, M.E. Gomes, J.F. Mano, R.L. Reis, Controlled release strategies for bone, cartilage, and osteochondral engineering-Part II: challenges on the evolution from single to multiple bioactive factor delivery, Tissue Eng. Part B: Rev. 19 (4) (2013) 327-352.

[40] P. Losi, E. Briganti, E. Sanguinetti, S. Burchielli, T. Al Kayal, G. Soldani, Healing effect of a fibrin-based scaffold loaded with platelet lysate in full-thickness skin wounds, J. Bioactive Compatible Polym. 30 (2) (2015) 222-237.

[41] M. Napolitano, S. Matera, M. Bossio, A. Crescibene, E. Costabile, J. Almolla, H. Almolla, F. Togo, C. Giannuzzi, G. Guido, Autologous platelet gel for tissue regeneration in degenerative disorders of the knee, Blood Transfusion 10 (1) (2012) 72.

[42] T. Spaková, J. Rosocha, M. Lacko, D. Harvanová, A. Gharaibeh, Treatment of knee joint osteoarthritis with autologous platelet-rich plasma in comparison with hyaluronic acid, Am. J. Phys. Med. Rehabil. 91 (5) (2012) 411-417.

[43] I. Andia, N. Maffulli, Platelet-rich plasma for managing pain and inflammation in osteoarthritis, Nat. Rev. Rheumatol. 9 (12) (2013) 721.

[44] G. Huang, S. Hua, T. Yang, J. Ma, W. Yu, X. Chen, Platelet-rich plasma shows beneficial effects for patients with knee osteoarthritis by suppressing inflammatory factors, Exp. Ther. Med. 15 (3) (2018) 3096-3102.

[45] S.A. Raeissadat, S.M. Rayegani, H. Hassanabadi, M. Fathi, E. Ghorbani, M. Babaee, K. Azma, Knee osteoarthritis injection choices: platelet-rich plasma (PRP) versus hyaluronic acid (a one-year randomized clinical trial), Clin. Med. Insights Arthritis Musculoskelet. Disord. 8 (2015) 1.

[46] T. Spaková, J. Rosocha, M. Lacko, D. Harvanová, A. Gharaibeh, Treatment of knee joint osteoarthritis with autologous platelet-rich plasma in comparison with hyaluronic acid, Am J Phys Med Rehabil (2012).

[47] Y. Zhu, M. Yuan, H. Meng, A. Wang, Q. Guo, Y. Wang, J. Peng, Basic science and clinical application of platelet-rich plasma for cartilage defects and osteoarthritis: a review, Osteoarthritis Cartilage 21 (11) (2013) 1627-1637.

[48] E. Kon, G. Filardo, A. Di Martino, M. Marcacci, Platelet-rich plasma (PRP) to treat sports injuries: evidence to support its use, Knee Surg. Sports Traumatol. Arthrosc. 19 (4) (2011) 516-527.
[49] K. Tsikopoulos, I. Tsikopoulos, E. Simeonidis, E. Papathanasiou, A.-B. Haidich, N. Anastasopoulos, K. Natsis, The clinical impact of platelet-rich plasma on tendinopathy compared to placebo or dry needling injections: a meta-analysis, Phys. Ther. Sport 17 (2016) 87-94.

[50] G. Gobbi, M. Vitale, Platelet-rich plasma preparations for biological therapy: applications and limits, Oper. Tech. Orthop. 22 (1) (2012) 10-15.

[51] S.K. Both, A.J.v.d. Muijsenberg, C.A.v. Blitterswijk, J.d. Boer, J.D.d. Bruijn, A rapid and efficient method for expansion of human mesenchymal stem cells, Tissue Eng. 13 (1) (2007) 3-9.

[52] T.A. Ahmed, E.V. Dare, M. Hincke, Fibrin: a versatile scaffold for tissue engineering applications, Tissue Eng Part B: Rev. 14 (2) (2008) 199-215.

[53] T.A. Ahmed, A. Giulivi, M. Griffith, M. Hincke, Fibrin glues in combination with mesenchymal stem cells to develop a tissue-engineered cartilage substitute, Tissue Eng. Part A 17 (3-4) (2010) 323-335.

[54] V.E. Santo, A.R.C. Duarte, E.G. Popa, M.E. Gomes, J.F. Mano, R.L. Reis, Enhancement of osteogenic differentiation of human adipose derived stem cells by the controlled release of platelet lysates from hybrid scaffolds produced by supercritical fluid foaming, J. Control. Release 162 (1) (2012) 1927.

[55] V. Cervelli, P. Gentile, M.G. Scioli, M. Grimaldi, C.U. Casciani, L.G. Spagnoli, A. Orlandi, Application of platelet-rich plasma in plastic surgery: clinical and in vitro evaluation, Tissue Eng. Part C: Methods 15 (4) (2009) 625-634.

[56] J.M. de Leon, V.R. Driver, C.P. Fylling, M.J. Carter, C. Anderson, J. Wilson, R.M. Dougherty, D. Fuston, D. Trigilia, V. Valenski, The clinical relevance of treating chronic wounds with an enhanced near-physiological concentration of platelet-rich plasma gel, Adv. Skin Wound Care 24 (8) (2011) 357-368.

[57] R.P. Russell, J. Apostolakos, T. Hirose, M.P. Cote, A.D. Mazzocca, Variability of platelet-rich plasma preparations, Sports Med. Arthrosc. Rev. 21 (4) (2013) 186-190.

[58] A. Roffi, B. Di Matteo, G.S. Krishnakumar, E. Kon, G. Filardo, Platelet-rich plasma for the treatment of bone defects: from pre-clinical rational to evidence in the clinical practice. A systematic review, Int. Orthop. 41 (2) (2017) 221-237.

[59] T.E. Foster, B.L. Puskas, B.R. Mandelbaum, M.B. Gerhardt, S.A. Rodeo, Plateletrich plasma: from basic science to clinical applications, Am. J. Sports Med. 37 (11) (2009) 2259-2272.

[60] G. Leitner, R. Gruber, J. Neumüller, A. Wagner, P. Kloimstein, P. Höcker, G. Körmöczi, C. Buchta, Platelet content and growth factor release in platelet-rich plasma: a comparison of four different systems, Vox Sang. 91 (2) (2006) 135 139.

[61] K. Lee, E.A. Silva, D.J. Mooney, Growth factor delivery-based tissue engineering: general approaches and a review of recent developments, J. R. Soc. Interface 8 (2011) 153-170.

[62] A. Solovieva, S. Miroshnichenko, A. Kovalskii, E. Permyakova, Z. Popov, E. Dvořáková, P. Kiryukhantsev-Korneev, A. Obrosov, J. Polčak, L. Zajíčková, Immobilization of platelet-rich plasma onto $\mathrm{COOH}$ plasma-coated PCL nanofibers boost viability and proliferation of human mesenchymal stem cells, Polymers 9 (12) (2017) 736.

[63] P.S. Babo, R.L. Pires, L. Santos, A. Franco, F. Rodrigues, I. Leonor, R.L. Reis, M.E. Gomes, Platelet lysate-loaded photocrosslinkable hyaluronic acid hydrogels for periodontal endogenous regenerative technology, ACS Biomater. Sci. Eng. 3 (7) (2017) 1359-1369.

[64] N. Boyd, A. Bradwell, R. Thompson, Quantitation of vitronectin in serum: evaluation of its usefulness in routine clinical practice, J. Clin. Pathol. 46 (11) (1993) 1042-1045.

[65] C.D. McFarland, C.H. Thomas, C. DeFilippis, J.G. Steele, K.E. Healy, Protein adsorption and cell attachment to patterned surfaces, J. Biomed. Mater. Res. Part A 49 (2) (2000) 200-210.

[66] C. McFarland, C. Thomas, C. DeFilippis, J. Steele, K. Healy, Protein adsorption and cell attachment to patterned surfaces, J. Biomed. Mater. Res. 49 (2000) 200-210.

[67] J.D. Humphries, A. Byron, M.J. Humphries, Integrin ligands at a glance, J. Cell Sci. 119 (19) (2006) 3901-3903.

[68] M. Roberts, S. Barry, A. Woods, P. van der Sluijs, J. Norman, PDGF-regulated rab4-dependent recycling of $\alpha \mathrm{v} \beta 3$ integrin from early endosomes is necessary for cell adhesion and spreading, Curr. Biol. 11 (18) (2001) 1392-1402.

[69] E.A. Turley, P.W. Noble, L.Y. Bourguignon, Signaling properties of hyaluronan receptors, J. Biol. Chem. 277 (7) (2002) 4589-4592.

[70] Y. Lei, S. Gojgini, J. Lam, T. Segura, The spreading, migration and proliferation of mouse mesenchymal stem cells cultured inside hyaluronic acid hydrogels, Biomaterials 32 (1) (2011) 39-47.

[71] M. Kisiel, M.M. Martino, M. Ventura, J.A. Hubbell, J. Hilborn, D.A. Ossipov, Improving the osteogenic potential of BMP-2 with hyaluronic acid hydrogel modified with integrin-specific fibronectin fragment, Biomaterials 34 (3) (2013) 704-712.

[72] L. Bian, C. Hou, E. Tous, R. Rai, R.L. Mauck, J.A. Burdick, The influence of hyaluronic acid hydrogel crosslinking density and macromolecular diffusivity on human MSC chondrogenesis and hypertrophy, Biomaterials 34 (2) (2013) 413-421. 